\title{
Chapter 2 \\ Setting up and Managing Automatic \\ Weather Stations for Remote Sites \\ Monitoring: From Niger to Nepal
}

\author{
Francesco Sabatini
}

\begin{abstract}
Surface weather observations are widely expanding for multiple reasons: availability of new technologies, enhanced data transmission features, transition from manual to automatic equipment, early warning for critical climate risks. One of the main objective is to rehabilitate/increase the density of existing network, by providing data from new sites and from sites that are difficult to access and inhospitable. Despite the increasing number of AWS's deployed, many remote sites are still not covered by surface observations. The goal is to improve AWS network planning, especially in regions where the scarcity of local trained personnel and funding availability to manage the instrumentation are relevant issues. Some consultancies performed in the past aimed to support, remotely and/or locally, National weather services, Public agencies, Local authorities and International organizations in defining and evaluating AWS's siting and selection. The efficacy of the results mainly depends on the accurate choice of the sites of installation (network plan), on the correct selection and description of instrumentation type to prepare the international tenders, on the training process to improve the AWS's management efficiency. The present chapter would discuss some of the main issues arisen from the experience gained during the institutional activities and consultancies in international projects.
\end{abstract}

Keywords Remote $\cdot$ Automatic weather station - Sensor

\subsection{Introduction}

An automatic weather station (AWS) is defined as a "meteorological station at which observations are made and transmitted automatically" (WMO 1992a). Despite the increasing number of AWS's deployed, many remote areas are not

F. Sabatini $(\bowtie)$

National Research Council-Institute of BioMeteorology (IBIMET),

Via Giovanni Caproni 8, 50145 Florence, Italy

e-mail: f.sabatini@ibimet.cnr.it 
covered yet by surface observations. The lack of local trained personnel and funding availability to manage the instrumentation, together with the risks associated with the safety of the equipment in remote and possibly insecure areas, represent the most relevant constraints. All the National weather services, public agencies, domestic organizations share these problems resulting more acute in developing countries (DC).

Furthermore to introduce and understand the role that AWS's can play in DC, we cannot limit ourselves to evaluate the performances of a standard AWS, but we should put them in the local specific context. As such the AWS "per se" do not change the efficiency of a Meteorological/Hydrological/AgroMeteorological Service if:

- They are not combined with others technologies such as computer science, remote sensing, GIS;

- the preparation of personnel is not very different from the past in terms of ability to deal with computers, electronic instrumentation, data transmission, data analysis, data combining on a geographical basis, choice and adaptation of models;

- there is not an international effort to prepare the tools such as manuals, software and learning procedures, to train personnel in an efficient and modern way (Maracchi et al. 2000).

FAO, GIZ, ICIMOD, AghryMet, World Bank, are international organizations that promote projects and cooperation, to sustain local Authorities in developing affordable weather observing networks. The efficacy of the results mainly depends on the sensors/systems selection (technical specifications), the accurate choice of the sites of installation and the evaluation of the observation network sustainability (economic and technical).

\subsection{Why RAWS?}

In the international scenario of AWS's, most of the developed countries have gone in for automation in their surface observational system since early 1970s. Countries like USA, Australia, Canada, China, India and many European countries are in the forefront. At the same time, it should be noted that no country has completely withdrawn their existing set-up of conventional surface observatories (WMO ET-AWS Final report 2008). AWS are being installed to enhance their meteorological observational network and many countries have their AWS installed in Antarctica or other reference sites (i.e. Himalaya, Nepal-EVK2CNR, Pyramid laboratory-Italy) for research purposes. Though AWS is unmanned by design, to check its security, exposure conditions and to do preventive maintenance, inspections to the sites are required for the upkeep of the AWS.

Moreover the availability of though, low power electronic equipment, encouraged the installation of RAWS's. In the past years, consultancies that I provided for 
FAO to draw technical specifications for AWS and AHyS to be installed in Northern Iraq, Somalia and Afghanistan confirmed this trend.

Example of RAWS networks are HKH-HYCOS (Regional Flood Information System Hindu Kush Himalayan Region (http://www.icimod.org/hycos), SHARE (Station at High Altitude for Research on the Environment), SNOTEL (Snow Telemetry, http://www.wcc.nrcs.usda.gov/snow/), THAMO (Trans-African HydroMeteorological Observatory (www.thamo.org).

WMO Integrated Global Observing System (WIGOS) aims at an improved collaboration and coordination between NMHSs and relevant national and regional organizations. It embraces the Global Observing System (GOS), the observing component of the Global Atmosphere Watch (GAW), the WMO Hydrological Observing Systems (including the World Hydrological Cycle Observing System (WHYCOS)) and the observing component of the Global Cryosphere Watch (GCW)—(https://www.wmo.int/pages/prog/www/wigos/wir/index_en.html).

Snowfall/snow depth measurements, undisturbed air quality observations, climate change studies, lead to select remote sites for ideal displacement of sensors (Nitu and Wong 2010). Even agrometeorology and hydrology applications are often dealing with the remoteness of rivers, valleys, mountains.

\subsection{Transition from Manual to AWS}

The WMO ET-AWS-5 Geneva 2008 (WMO report 2008), agreed that human observers were able to integrate and classify a wide range of information needed for full description of weather events. With the advent of AWS, particular areas such as visual observations, cloud classification and weather type identification are handled poorly or not at all, by an AWS unattended by observer. On the other hand, AWS provide benefits in frequent, regular, objective and consistent measurements and can be located in any environment, including extremely remote and harsh conditions.

The transition to AWS is often instigated by a perception that these systems are cheaper to operate and easier to manage than human observers. This was not the experience of a number of member countries. Therefore, it identified a number of responsibilities and costs that may not be immediately apparent to those that adopt automatic systems. (Shanko 2015).

The change for automation is a reality in all networks (India, Nepal, Lebanon, Niger, Ethiopia, etc.) and the careful management of the transition process is needed to protect data user needs. Canada created a Change Management Board (CMB), to provide a forum for network planners, operational managers and data stakeholders to discuss strategic issues regarding the transition process.

Before embarking on automation of their network, Members and/or local organizations should consider (i) the resource requirements, (ii) potential gains and losses, (iii) how to manage this transition, (iv) Training/professional improvement, (v) homogenization of different datasets. 
M.J. Molineaux (Molineaux 2010) suggested a preliminary list of guidelines which would assist in the process of converting to automatic systems:

- Management of network change

- Defining and assigning responsibilities

- System costing

- Parallel testing (Traditional vs. automatic)

- Metadata

- Data quality and reliability

- User requirements

- Access to data and metadata

In the last years, many AWS manufacturers have improved their products, allowing researchers, field assistants and operators to set up unattended data collection with several options depending on the field of application. Despite the availability of relatively cost-effective automatic stations, traditional instruments can still play an important role, as an alternative or back-up for the automatic network, especially in areas where a lack of personnel trained in electronic equipment is a limiting factor (Table 2.1).

The WMO ET-AWS 6-2010 included the following considerations in the Final report. The meeting considered the report prepared by the $\mathrm{CCl} \mathrm{ET}$ on Climate Database Management Systems (ET-CDBMS), in particular the observing requirements and standards for climate. The importance of retaining some manual stations for optimizing the complementary aspects of AWS and manual stations was

Table 2.1 Comparison between traditional and automatic system

\begin{tabular}{l|l|l}
\hline Type & Advantages & Disadvantages \\
\hline $\begin{array}{l}\text { Manual } \\
\text { (Direct reading) }\end{array}$ & $\begin{array}{l}\text { Simple use } \\
\text { Rapid installation } \\
\text { Immediate utilisation } \\
\text { Reliability } \\
\text { No power required }\end{array}$ & $\begin{array}{l}\text { It needs an operator for data observations } \\
\text { Slow data transfer from paper reports. } \\
\text { Errors due to incorrect transcription. } \\
\text { Low number of readings available }\end{array}$ \\
\hline $\begin{array}{l}\text { Mechanical } \\
\text { (Chart recording) }\end{array}$ & $\begin{array}{l}\text { Simple use } \\
\text { Simple maintenance } \\
\text { Reliability } \\
\text { Rapid installation } \\
\text { No power required }\end{array}$ & $\begin{array}{l}\text { It needs an operator for chart replacement } \\
\text { Errors during chart replacement and } \\
\text { transcription } \\
\text { Slow data transcription from strip diagrams } \\
\text { recording }\end{array}$ \\
\hline $\begin{array}{l}\text { Fast data acquisition } \\
\text { Data real time visualization sensitivity to mechanical vibration } \\
\text { and/or transmission } \\
\text { Large amounts of } \\
\text { observations } \\
\text { Data pre-processing } \\
\text { Control output (alarms, water } \\
\text { supply systems, etc.) } \\
\text { In some cases low cost } \\
\text { systems can be exploited }\end{array}$ & $\begin{array}{l}\text { Power supply required } \\
\text { High professional maintenance } \\
\text { Expensive sensor management } \\
\text { Specialised laboratories for sensor } \\
\text { calibration } \\
\text { Electromagnetic interference on electronics }\end{array}$ \\
\hline
\end{tabular}


emphasized. For a GIZ consultancies in Nepal I suggested to install RAWS together with a new set of manual sensors in order to facilitate the transfer process from traditional observing procedures to new technologies (Figs. 2.1 and 2.2). The

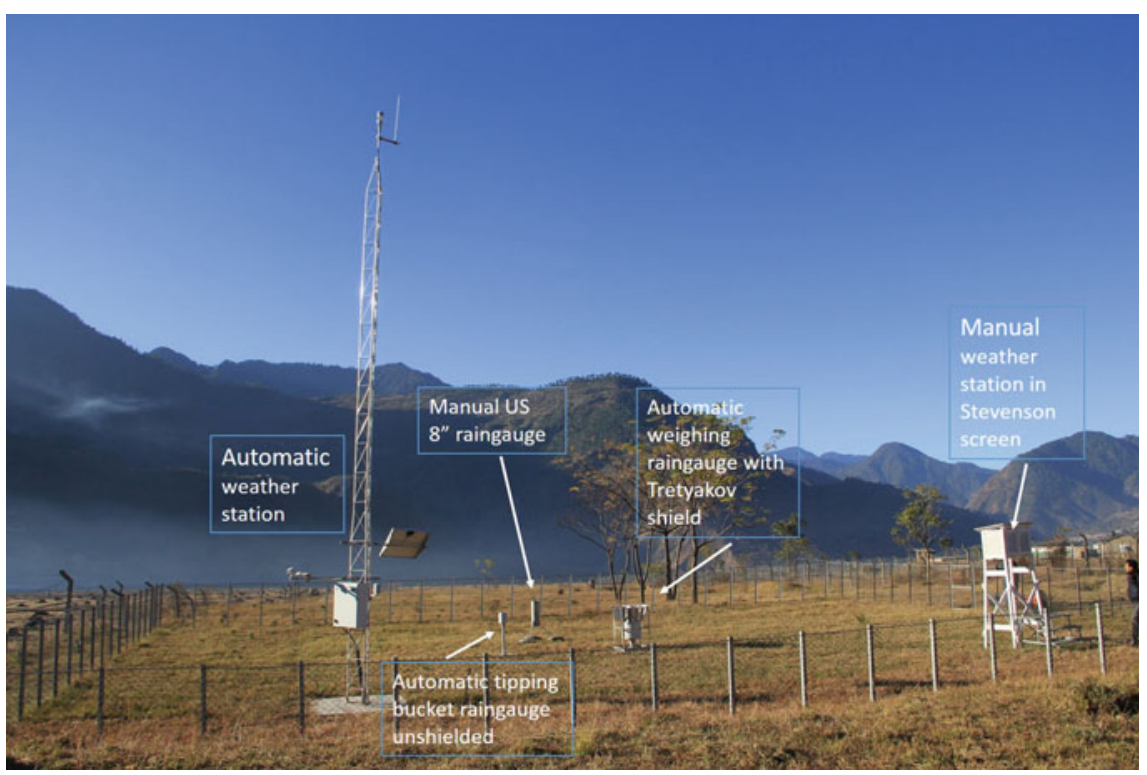

Fig. 2.1 Chainpur Nepal-Manual and AWS

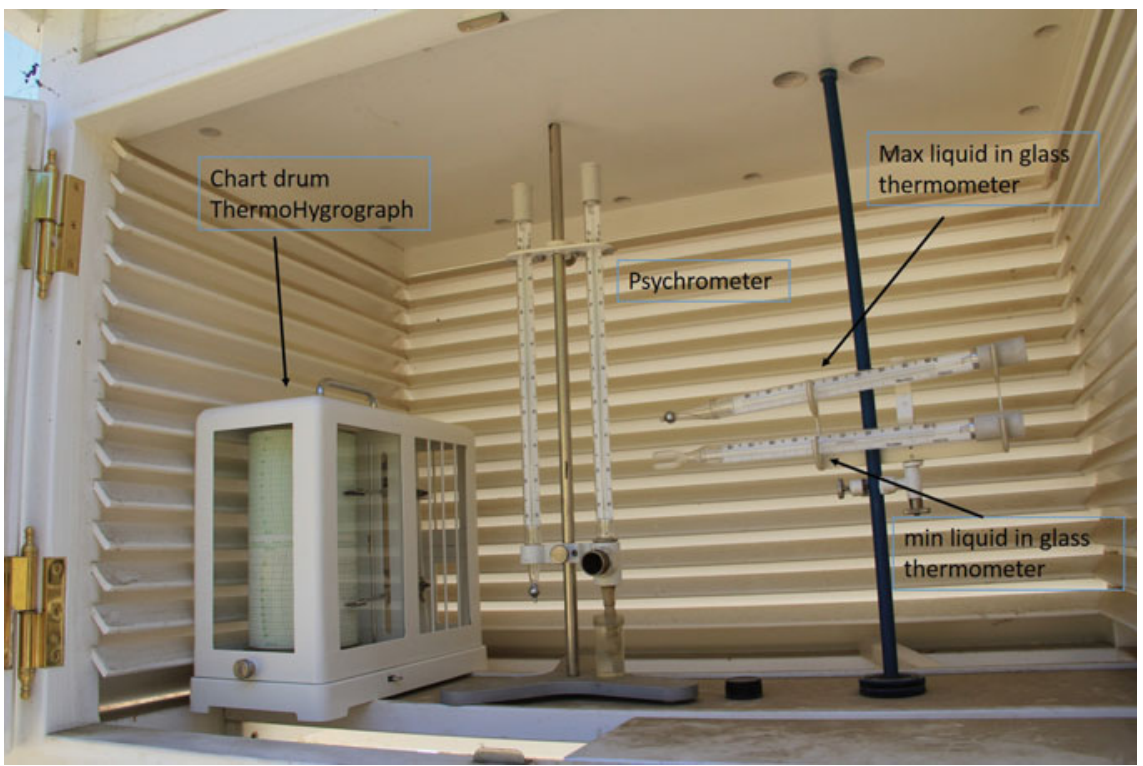

Fig. 2.2 Rara Nepal-Manual station in Stevenson Screen 
observer should be kept in charge until the met service is not ready to rely on automatic equipment and to build up a dataset from manual and automatic stations in order to evaluate how this process may affects the observations.

\subsection{RAWS Configuration and Requirements (Technical Specifications)}

The Manual on the Global Observing System (WMO 2013), states the General requirements of a meteorological station as follows: "All stations shall be equipped with properly calibrated instruments and adequate observational and measuring techniques, so that the measurements and observations of the various meteorological elements, are accurate enough to meet the needs of synoptic meteorology, aeronautical meteorology, climatology and of other meteorological disciplines."

The requirements for AWS instruments have to take into consideration all aspects related to the ability to provide relevant and representative measurements over their entire life cycle.

The requirements for sensors installed at AWS can be ranked into three basic categories, all contributing to the long term sustainability of AWS data:

- Requirements related to the measuring performance of instruments: the ability of an instrument to provide measurements with a stated uncertainty over the specified operating range and condition;

- Requirements related to maintaining the traceability of measurements over the operational cycle; and

- Requirements related to the operational reliability of AWS sensors, which include features that enable their operation for extended periods, within the expected measuring performance, with minimum human intervention over their entire operating range. (WMO ET-AWS-5 2008)

These requirements and standards for AWSs operating in remote regions fall under several different broad aspects.

Telecommunications. GSM/GPRS is cheaper than Satellite communication. These networks are now available almost everywhere in many emerging countries. GPRS hardware is much cheaper as compared to satellite systems. GPRS networks may be used wherever they are available whereas satellite communications (such as IRIDIUM or ORBCOMM) have been used where GSM/GPRS networks are unavailable.

Power. Solar panels with backup batteries are a useful power source for AWS at remote areas. Solar panels and batteries are easily available and affordable in many regions. Sometime the use of wind turbines has been investigated at some sites, to integrate solar power (i.e. in CMA, China network). For specific sites, especially during wintertime, with low solar intensity and low temperatures, solar solutions 
alone do not supply reliable off-grid power, especially in critical weather and the dark seasons, so the use of fuel cell deserve mention. (i.e. New-Zealand remote snowfall stations)

Sensors. Robust and high quality sensors are suggested for remote areas. Sensors and the platform employed should be suitable for remote diagnostics and troubleshooting in order to avoid frequent inspection visits..

AWS equipment. The cost of the data loggers and communication devices has come down drastically with recent advances in electronics technologies, BUT equipment, which can work over an extended temperature range, are still expensive. Robust data loggers and communication devices are required which can work in extreme environments e.g., temperature and prolonged time with high humidity values.

AWS enclosure. In extreme weather areas waterproof box should be rust proof and salt resistant. Normally we go for standard IP65-66 or NEMA 4 protection grade. These enclosures should be made of suitable material or properly shielded so that inside temperature does not increase considerably, causing malfunction to the electronic equipment or batteries. High rainfall rates can cause water infiltration, so the connector and core hitches exposure to the environment mast be minimal.

Radiation shields. Radiation shields should be rugged and allow free airflow over the sensors, so wooden or plastic Stevenson screens should be employed. Normally fan-aspirated shield are not suggested unless strictly required.

Earthing. AWS equipment is often damaged by lightning strikes. Appropriate conventional or maintenance-free earthing, could be very effective in the long run. State-of-the-art lightning arrestors together with maintenance-free earthing at the site could reduce AWS faults due to lightning.

Calibration of sensors and maintenance of stations. Tropical; mountain and dry regions have peculiar problems in maintenance of AWS sensors due to dust deposition or frost/snow damages. Though AWS are generally unmanned by design, regular visits to a site are required to check its security, exposure conditions and for performing preventive maintenance. The costs of maintenance, calibration and running expenses for an operating AWS network far outweigh the initial purchase expense, so these expenses should be kept in mind before planning the siting and installation of an AWS network. Calibration of sensors should be performed at least once or twice per year. Availability of manpower and funds are major constraints in accomplishing these tasks.

Safety. In remote regions security of AWS equipment has become a major concern. It is quite common that there are many thefts of solar panels and batteries from the AWS sites. I had experienced 2 solar panels stolen and 1 cup anemometer broken for pure vandalism, The general public now understand that solar panels and batteries can be used in domestic or mobile applications (i.e. Van, Campers). Public participation of local people and awareness programs can help to reduce these events. The participation of Non-Governmental Organizations (NGO) can be also considered. The installation near military camps or police stations is often adopted as a suitable compromise between safety vs RAWS representativeness. Adoption of WMO siting classification guidelines, is important for exhaustive description of 
sensors exposure. M. Leroy of Météo-France proposed a standardised method to describe siting classification for the main variables measured at AWS, that are now incorporated in the WMO-CIMO reference guide (WMO Technical Guide $\mathrm{n}$. 8 2012)

When deciding to buy an AWS the first step is to design the exact configuration (i.e. the type of sensors, amount of memory of the data-logger, power required, etc.). The main characteristics should be: Reliability; Robustness (toughness); Simple operation; Reduced level of maintenance; Installation of few sensors and estimation of other parameters.

Some examples:

- Instead of using a standard "A" Pan evaporimeter tank, which requires frequent interventions, it is better to estimate the evaporation from the other meteorological variables such as air temperature and humidity, wind speed, solar radiation, etc.

- For wind speed and direction, bi-dimensional sonic anemometers can be used which can replace traditional cup anemometers and vane sensors. Sonic anemometers are now comparable in terms of costs and signal output features; as they have no moving parts the maintenance operations are greatly reduced. Virtually no recalibration procedures are required.

- The net radiation can be estimated from the global radiation.

- If soil moisture sensors have to be installed, Time Domain Reflectometry sensors (i.e. Delta_T Thetaprobe, Campbell CS610) ${ }^{1}$ offers low maintenance operations and long term stability. Alternatively, this parameter could be estimated from soil water balance methods.

Furthermore, if the AWS is not part of a reference climate network, the adoption of a passive (natural ventilation) solar radiation shield for Air temperature and Relative humidity sensors is suggested (no power required for the fan and no fan failures). Possible errors on air temperature observation during unfavorable conditions (wind speed $\leq 1 \mathrm{~m} / \mathrm{s}$ and global solar radiation $>800 \mathrm{~W} / \mathrm{m}^{2}$ ) are expected. The accuracy of thermometer can be of $\pm 0.3{ }^{\circ} \mathrm{C}$ instead of $\pm 0.1{ }^{\circ} \mathrm{C}$.

The data logger (Fig. 2.3) has to meet the following generic requirements: portability, prolonged field deployment, flexibility, rapid sampling over multiple channels, small size and weight, low power drain, non-volatile data storage, and battery-backed real time clock. ADC (Analog-to-Digital converter) should have at least $14-16$ bit resolution and a voltage range of $0-2.5 \mathrm{Vdc}, 0-5 \mathrm{Vdc},-5 /+5 \mathrm{Vdc}$ or autorange. SDI-12 port, RS-485 and RS-232 input, Digital inputs for tipping rain gauge bucket, pulse anemometer and digital leaf wetness sensors. Normally up-to-date systems have these features. One of the following arrangements can be considered:

\footnotetext{
${ }^{1}$ The names are necessary to report factually on available data; however, the author neither guarantees nor warrants the standard of the product of specific manufacturer, and the use of the name by the author implies no approval of the product and manufacturer to the exclusion of others that may also be suitable.
} 


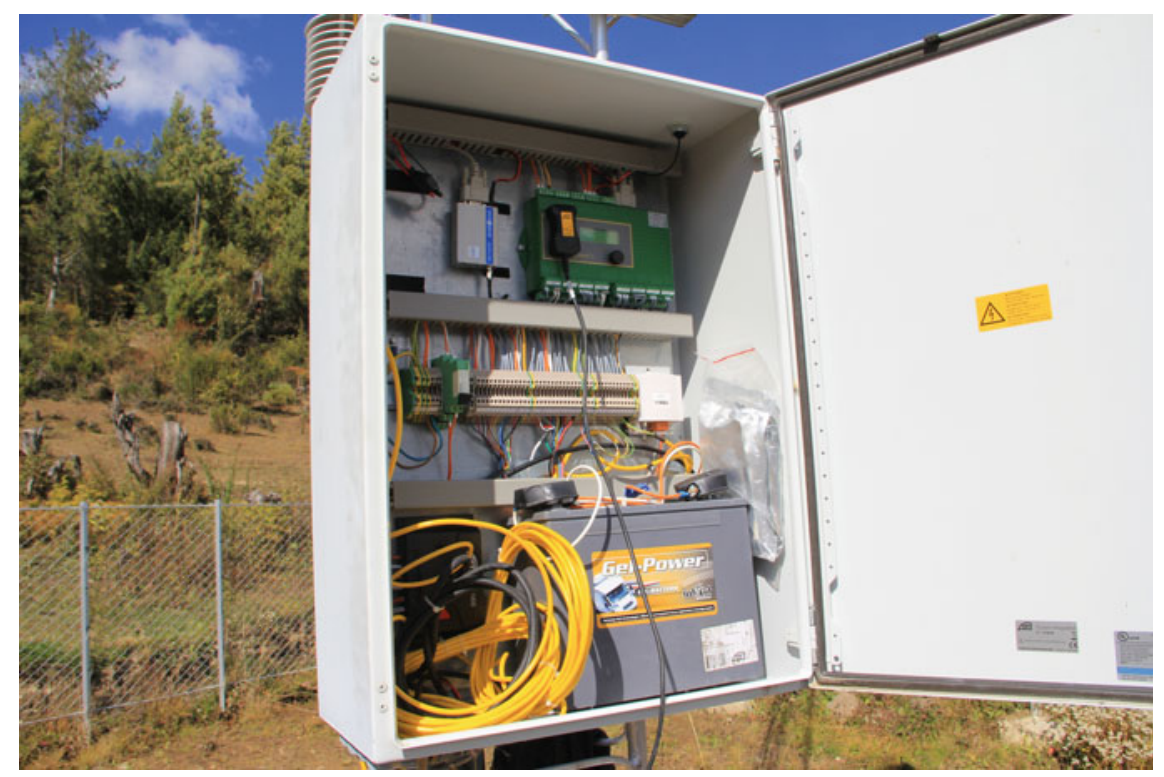

Fig. 2.3 Rara Nepal. OTT data logger and data transmission modem in IP65 enclosure

1. A complete AWS as a turnkey system (data-logger plus sensors, telemetry option, wires, software, power device, mast, sensors brackets, etc.), assembled and configured upon request by the manufacturer, or

2. A composite arrangement of one or more items (i.e. the data-logger, plus specific sensors chosen from other company's catalogues + telemetry system), configured and customized by the user.

\subsection{Data Transmission}

Remote data transmission is an important feature which adds more complexity to the system (Fig. 2.4). In particular it requires a careful evaluation in terms of:

- Power. It may be one of the option of the system that drains the most current, especially during data transmission).

- Cost of the equipment (modem, antenna, improved power supply...).

- Cost of data transmission (i.e. future sustainability).

- Routine checks towards provider for GSM/GPRS or satellite services, i.e. available credit on the SIM for each contract (each station + base station); GSM/GPRS tariffs, comparison of the expected cost to the invoices received. 
Fig. 2.4 Available data transmission systems

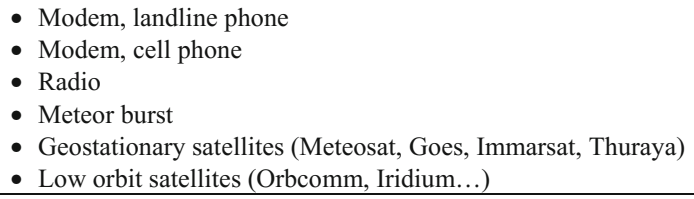

Once the site of installation has been accurately identified, a specific selection of the telemetry option can be based upon:

- Presence of an affordable phone landline at the site of installation.

- GSM-GPRS/CDMA cell phone coverage at both the site of observation and at the base station.

- Radio frequency availability and license restrictions. Distance of the observation sites from the base station. (Signal repeaters required?).

Normally we choose the satellite option to overcome the disadvantages of the other systems. Coverage of the service as stated by the providers is normally affordable. It can be more complex and/or expensive with respect to the other telemetry options (unless it is possible to access a Meteosat platform as a recognized National Meteorological Service) (Fox et al. 2007).

Meteor Burst wide range data transmission systems deserve mention. This technology is free from transmission fees, but the hardware is very expensive (especially the base station). It relies on the phenomenon of reflecting radio waves off the ionized trails left by micrometeors as they enter the atmosphere and disintegrate. These trails exist in the $80-120 \mathrm{~km}$ region of the earth's atmosphere, and reflect the RF energy between two stations. The height of the trails allows over-the-horizon communication at distances up to $2000 \mathrm{~km}$. This option is particularly well suited for long-range, low data rate applications for both messaging and data acquisition, like SNOTEL network. (Schaefer and Paetzold 2000).

Common communication methods can be via dial-up modems, leased-lines, radio (licensed or unlicensed frequencies) and satellite. Combinations of these can be used as well. For example, RTS Kathmandu (Nepal) developed a device equipped with CDMA, GPRS and Satellite modems: if the CDMA and/or GPRS line fails the systems automatically switch to satellite modem to ensure data transmission. The negative aspect is that the customer has to keep two contracts active instead one, but when a reliable early warning system is required, this option may result of great interest.

Each data transmission method has its advantages and disadvantages (Table 2.2). Frequency of polling and speed should be balanced with cost and power supply availability at the remote station. Site requirements may dictate that communications be close to real-time or not, depending on the applications. With radio systems, it is especially important that enough time and money be allocated to design and implement the best system possible. Generally, communication speed 


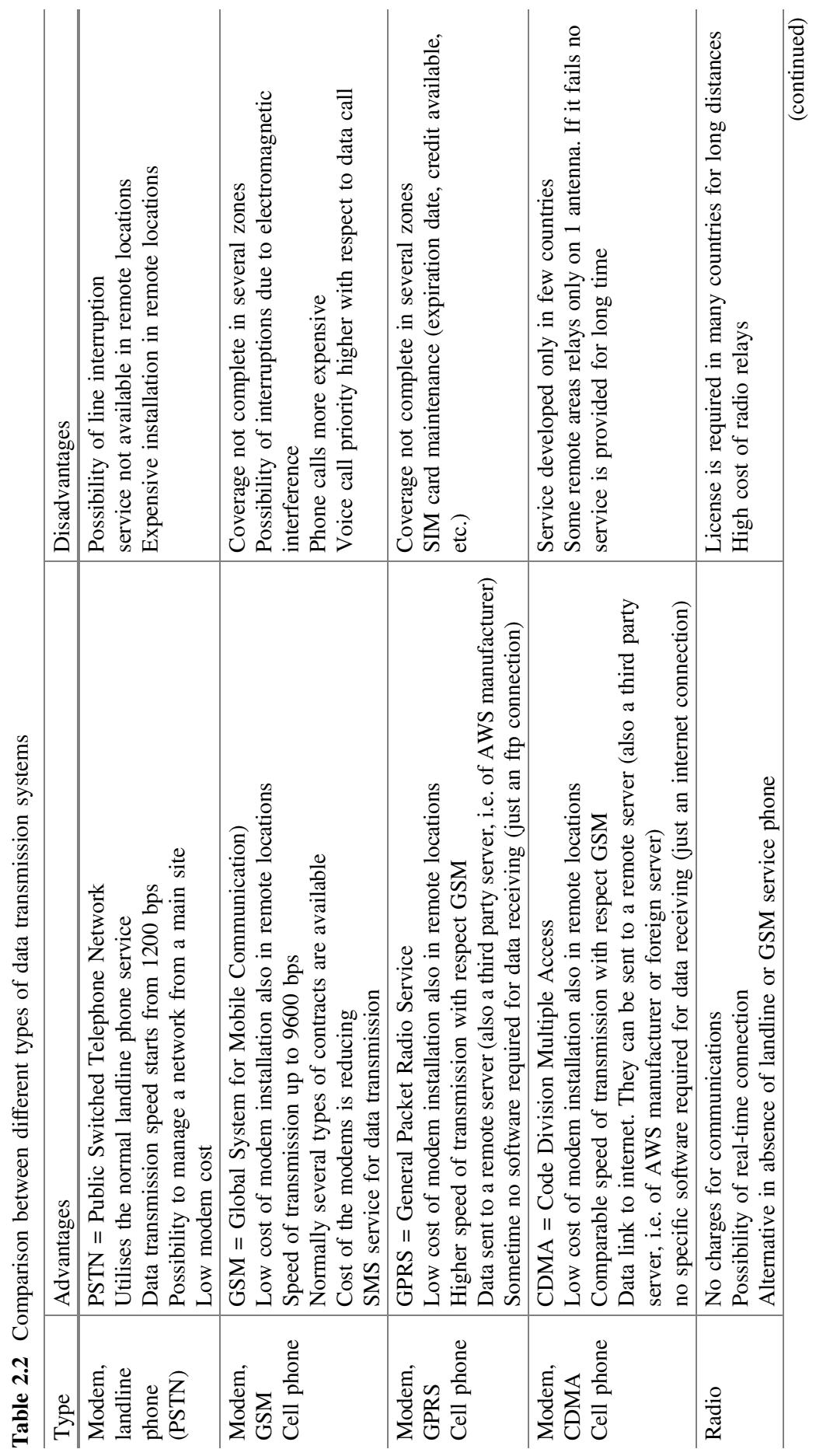




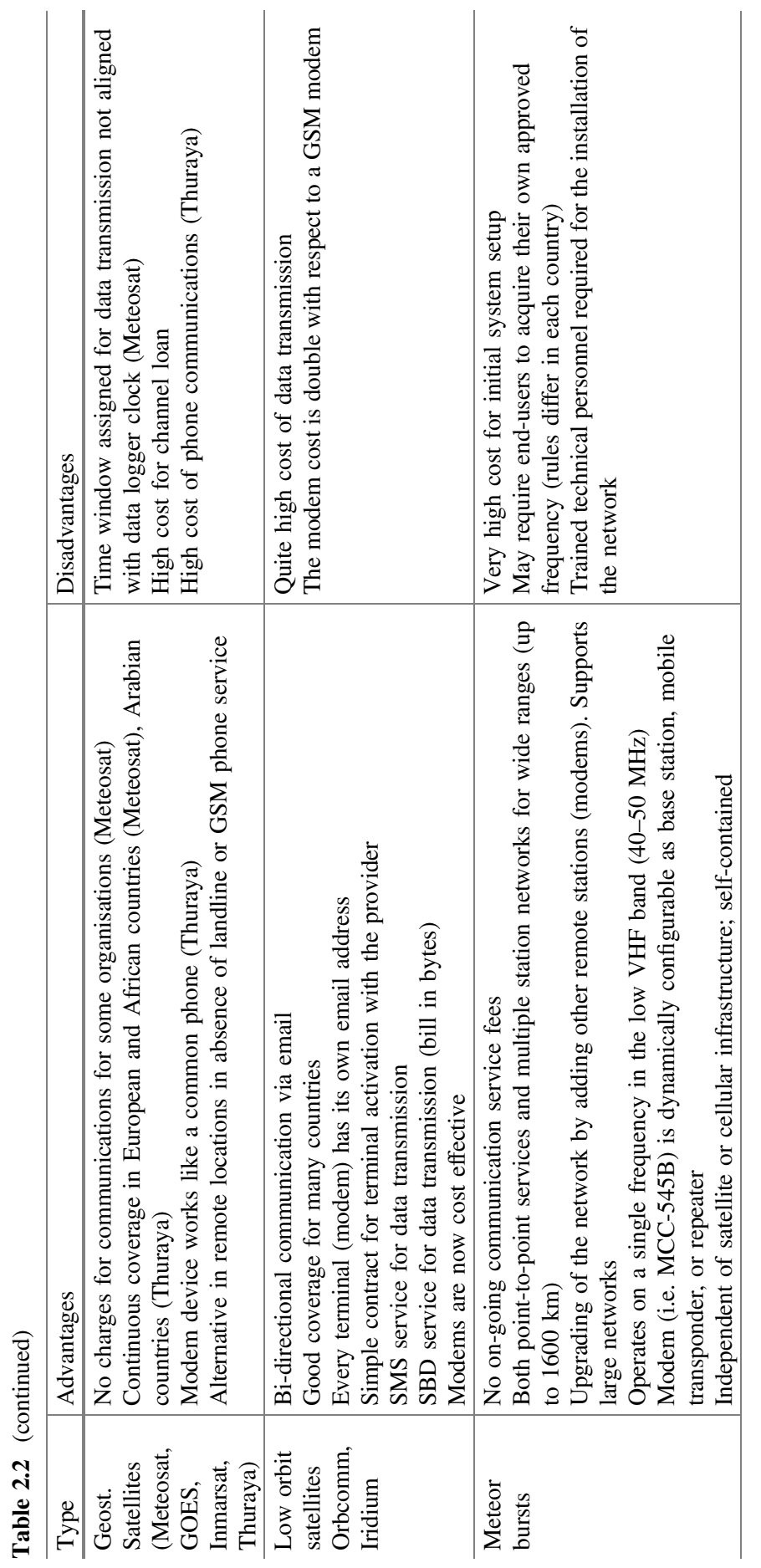


and availability relate directly to cost. Some modems support a communication scheme that can substantially reduce power requirements, resulting in a battery and panel size reduction of over $50 \%$.

A poorly designed system can waste money in terms of troubleshooting and maintenance cost. Mr. Karl Blauvelt in his technical paper on AWS maintenance (Blauvelt 2000) talking about cell phones reported "...When these phones work, they are great. When they do not, they are a headache." I think that things have improved nowadays but accept the fact that is never fault of the phone company or of the network provider. Moreover, if you setup a GSM/GPRS configuration in a country it may be different in another country, so preliminary local field tests are mandatory before going for the final installation.

\subsection{RAWS Management}

The WMO ET-AWS 5 (2010 established a list of advances and limitations in AWS technology. The main advances concern telecommunications means and ability of internal diagnostic to optimize the maintenance.

Rodica Nitu of Environment Canada reported that the decreasing cost of an AWS make them more affordable and attractive, however, it has to be recognized that the cost of AWS stations remains marginal compared to the initial and running costs of a network. It is mandatory to evaluate this aspect to avoid useless investments by lack of subsequent network management, maintenance, calibration and training.

There is a wide range of configurations of AWSs for surface measurements available; high end systems (e.g. for airport, climate, micrometeorological applications) are most often user specific configured. This foresees trained local personnel to manage the equipment.

The customers may tend to choose a turnkey system managed by a third party (manufacturer, local agent/distributor), if they cannot rely on trained personnel. The RAWS maintenance is the first aspect to be taken into account; type and number of sensors to be choose is fundamental in the planning phase. As far as I know, there is no maintenance-free automatic weather equipment but we can work at reducing the inspections operations selecting appropriate sensors, as discussed in the RAWS configuration paragraph above.

No moving parts is one of the best features of a sonic anemometer because it reduces failures typical of the traditional cup anemometers. Non-catchment rain gauge type represents an alternative to standard rainfall collector for long time deployment in remote sites, even if the scientist are still validating their responses against field reference systems. Intercomparison campaigns organized by WMO show interesting perspectives for their use in multiple precipitation regimes: rainfall, snow, mixed rain-snow, drizzle, etc. The absence of a collector and/or moving parts led to more reliable observations, maybe of less accuracy, but less affected by some error source. 
The operational procedures within a NMHS is a set of processes relating to both institutional and technical management aspects. In this context, the leadership shall be aware of the importance of implementation of the remote sites monitoring network in their observation network (Hall 2007). To help improve AWS's management I would recommend the following to those who are responsible of the observation network.

Management:

1. To establish clear working processes (related to the RAWS implementation) that are described and documented. The process descriptions identify responsible persons and staff activities, as well as relevant documentation and information flow.

2. To officially appoint local agent/company for the maintenance of the AWSs of the monitoring network, at least in the start-up phase.

3. To nominate one person who shall actively interact regarding technical aspects with local company/distributor and relevant organizations engaged in the monitoring network: system maintenance, routine checks, data management, data processing. He/She shall have basic experience in computer science and hydrology/weather data management and will participate in the inspection visits to the sites. He/She should be responsible for compiling metadata about the sites/stations.

4. To provide equipment and train the personnel identified in point 3) on the use and practice of AWSs and AHySs and software management.

5. To set a calendar of meetings with local company/distributor and relevant organizations personnel (i.e. every 6 months) to evaluate and discuss the data received, to prepare and schedule both extraordinary and ordinary maintenance inspections to the sites, to periodically check telemetry costs and performances.

6. To fully support capacity building efforts to help develop its own service. Some help would be provided immediately through the distribution of WMO guidance material and promoting activities such as training, publications and technical advice.

Technical issues:

1. To keep and maintain in good condition a complete AWS in their laboratories, to perform tests, routine checks, training and related activities.

2. To keep and maintain in good condition spare parts or new accessories such as batteries, solar panels, data logger, GPRS modem, sensors, and cables for the network of automatic stations. At least one complete system for each type of station should be available in stock as a back-up in case of failures or recalibration.

3. A Notebook equipped with USB and/or USB-RS232 adapter and the communication and elaboration software is fundamental for sensor and system checkup.

4. To setup one portable sensor kit to be used as a "travelling standard" for comparison against the deployed sensors. 
Field inspections/maintenance:

1. Give consistency to sensor sampling and data acquisition intervals to the AWS and RAWS configurations.

2. Double-check all the system configurations (i.e. sensor conversion factors, height of installation, sensor exposure).

3. Implement their "Field Form Report" with data comparison against portable and/or traditional sensors, where applicable.

4. Set into the configuration one or more "awakening intervals" for remote modems (i.e. two or three intervals of $1 \mathrm{~h}$ each per day), in order to set communications for routine checks or remote configuration modifications.

5. Interact with relevant organizations to strengthen practical training on AWS management and data evaluation. This will be supportive for the person(s) in charge of network maintenance.

6. Develop a document that describes work processes typical for observation generation, making reference to the relevant WMO documents (Sabatini 2010).

\subsection{Low-Cost RAWS: A Suitable Choice?}

The WMO ET-AWS-6 2010 agreed that there is a need for continuous monitoring of advances of AWS technology for timely and comprehensive advice to WMO Members. Research Institutes, Universities, and international organizations are following the AWS technologies evolution as well, in order to suggest up to date solutions for meteorological and micrometeorological monitoring. Advances in technology and the decrease of costs of sensors and data loggers led to the development and integration by manufacturers of compact/low-cost weather stations. This is significantly driven by the ability to integrate and display data from multiple sources, in real time and near real time, primarily through the internet. (WMO ET_AWS-6-Final report 2010)

Computer science, real-time data and metadata transmission, Smartphones, Internet, electronic devices, led to the foundation of open access monitoring platforms.

Data-sharing, participative approach, citizens science, data interoperability are the keywords of this process. A common base is that these platforms are based on low-cost (or very low-cost) equipment because it should serves as much volunteers/observers as possible.

The compact AWSs are increasingly used for agricultural, urban meteorology. They normally integrate inexpensive sensors of performance of measurement yet to be assessed. Most of these AWS include pre-programmed data processing algorithms that are the property of the integrator.

Given the affordable cost, including installation, the small foot print required, and the increased availability, these platforms have a good chance to capture a large share of the market for producing meteorological data for various applications. 
Advantages:

- compact, self-contained;

- low-cost;

- easily deployable;

- integrating up to date forms of communication which allow networking and spatial integration of data.

- ability to establish a denser network;

- real-time and on site storage of data;

- potential to be used as a subset of a fully equipped AWS (e.g. temperature and precipitation);

Disadvantages:

- Reduced interaction (Black box) between the system and the customer

- Third-party sensors or transmission devices cannot be implemented

- Metadata absent or poorly reported

- Lack of standardized observations procedures

(WMO ET-AWS-6-2010)

Manufacturers like Davis (USA, CA), Pessl (Austria), Caipos (Austria), Decagon (USA), Onset (USA), Netsens (Italy), mainly propose low cost (or cost-effective) equipment for environmental monitoring and agrometeorological applications. Some of them provide to customer an AWS with some optional configurations, powered by a Solar Panel, plus an internal battery and transmits weather data in quasi real time (i.e. 15 to $60 \mathrm{~min}$ ) over GSM/GPRS.

The system can also send SMS Alarms upon specific events like frost, rain, temperature, etc.

Data are regularly uploaded to a web platform developed by the manufacturer(password protected). The user besides checking the weather data, can access additional packages for Weather Forecast, Disease prediction models and Irrigation Management The user pays a flat yearly fee that includes the Internet traffic and the web domain management.

More advanced research institutes or public organizations tend to build-up AWS's based on very low cost acquisition board (i.e. Arduino, Raspberry) that offer a large number of options and devices (multiplexer, Wi-Fi boards, GPRS modem, applications notes developed by the community). These systems are normally limited to specific projects for specific applications for a defined amount of time (i.e. 1 to 3 years), because the overall toughness of the system is not normally comparable to the traditional AWS's even if examples of services based on this approach exist. The power consumption is also an issue since low-cost systems normally drain more power with respect advanced data loggers. This then has an impact on the size of the batteries and of solar panels.

Info4Dourou and Info4Dourou 2.0- sustainable management project (http:// cooperation.epfl.ch/Info4Dourou) aims at increasing the availability of natural resource information for local people of Burkina Faso and improve environmental data collection using low-cost local-made automatic stations. The EPFL-CODEV Lausanne, Switzerland developed a low cost hydro-meteorological observation 
network to reinforce and increase water and natural resource management capacity by engaging new technology for development and to increase the ability of the rural community to adapt to changing environmental pressures.

CNR-IBIMET developed its own infrastructure (www.sensorwebhub.org), to receive data from multiple type of homemade sensors/stations, even mobile systems, in order to provide an open common platform compliant to OGC approach towards the world of IoT (De Filippis et al. 2015).

The adoption of the low-cost approach for remote sites meteorological monitoring deserve attention, since it can integrate conventional networks providing useful information otherwise not available.

\subsection{Conclusions}

Surface meteorological monitoring at remote sites requires a decision process that result in a cross-cutting activity among a given Organization. The applications, the site accessibility, harsh environments, lack of data transmission platforms and power supply options, may led to a very difficult selection procedure.

As already pointed out by the present chapter the most important constraints are represented by: (i) the limited technical capacity in the local organizations to operate and maintain the systems and (ii) the risks associated with the safety of the equipment in remote and possibly insecure areas.

Upon my experience the best approach would be represented by a step by step, progressive installation, of AWS at the remote sites. Since the skill of personnel grows normally up according to the complexity of the network, the multiple setup of AWS's can pose problem of sustainability at the beginning.

Whatever the sites position an expensive part of the whole plan is also represented by the software/hardware infrastructure and the processing center for data management (normally installed at the organization headquarter), but the aspect of maintenance of several surface observation sites represents a very important aspect.

Unfortunately, this approach rarely matches those of the national/international implementation projects: even well-conceived initiatives are normally focused on a specified amount of years (3-5 years), without an extended follow-up process. Once the project expires, the network is no longer appropriately managed and missing inspections lead to lack of data in the observations series and hardware failures. Sometime the result is a set of several AWS's generations, not interoperable, installed for different projects and from different manufacturer.

WMO-RTC's should accompanying this transition process addressing specific training course on AWS management and IT integration, but again the synchronization among national and international bodies in not that efficient.

Anyway the RAWS's are expanding despite their difficult management. This process will continue in the next years for multiple applications: water resource monitoring, solid precipitations, climate change studies, basic climatology, ground truth for remote sensing analysis. 
The selection and management of robust and well maintained RAWS is a real challenge for whatever country is planning their implementation in the present observing system. WMO, FAO, AghryMet, ICIMOD and related international projects could play an important role in this process, in order to adopt appropriate approaches compliant to up-to-date techniques.

\section{References}

Blauvelt, K. 2000. Maintenance and calibration manual for the automated weather data network. Calibration facility, High plains climate center. University of Nebraska-Lincoln USA.

De Filippis, T., L. Rocchi, and E. Rapisardi. 2015. SensorWeb Hub infrastructure for open access to scientific research data. Geophysical Research Abstracts 17. EGU2015-7847-2.

Fox, J., P. Geissler, and R. Worland. 2007. Versatile Iridium Campbell link,. (1) British Antarctic Survey (j.fox@bas.ac.uk). Geophysical Research Abstracts 9. 01810. SRef-ID: 16077962/gra/EGU2007-A-01810. (C) European Geosciences Union.

Hall, B.L., and T.J. Brown. 2007. Comparison of weather data from the remote automated weather station network and the North American Regional Reanalysis. In 87th AMS Annual Meeting.

Maracchi, G., F. Sabatini, and M.V.K. Sivakumar. 2000. The role of automated weather stations in Developing Countries. In Proceedings of the International workshop on "Automated weather stations for applications in agriculture and water resources management: Current use and future perspectives". 6-10 March 2000. Lincoln, Nebraska, USA.

Molineaux, M.J. 2010. Automation of surface observations. Development of guidelines and procedures for the transition from manual to automatic weather stations. WMO CBS - Opag on Integrated observing systems. Expert team on requirements and implementation aws platforms (Et-Aws). Sixth session. Final report. Geneva, Switzerland, 20-23 April 2010.

Nitu, R., and K. Wong. 2010. Measurement of solid precipitation at automatic weather stations, challenges and opportunities. Meteorological Service of Canada, 4905 Dufferin St, Toronto, ON, M3H 5T4, Canada.

Sabatini F. 2010. Recommendations for the design of a system for acquisition, transmission and storage of Hydro-Meteorological data on the Kailash sacred landscape in Nepal. Project title: Supporting climate change adaptation and biodiversity conservation in the Kailash landscape. Final report.

Schaefer, G.L., and R.F. Paetzold. 2000. SNOTEL (SNOpack TELemetry) and SCAN (Soil Climate Analysis Network). In Proceedings of the International workshop on "Automated weather stations for applications in agriculture and water resources management: Current use and future perspectives". 6-10 March 2000, Lincoln, Nebraska, USA.

Shanko, D. 2015. Use of automatic weather stations in Ethiopia. National Meteorological Agency (NMA) report, Addis Ababa, Ethiopia.

WMO. 2010. Guide to meteorological instruments and methods of observation, Technical Manual $n^{\circ} 8$. $7^{\text {th }}$ Edition 2008 updated 2010. Geneva, Switzerland: World Meteorological Organization.

WMO. 2008. Final report. World Meteorological Organization-Commission For Basic Systems Opag On Integrated Observing Systems. Expert Team On Requirements for Data From Automatic Weather Stations-Fifth Session-Geneva, Switzerland, 5-9 May 2008.

WMO. 2010. Final report. World Meteorological Organization-Commission For Basic Systems Opag On Integrated Observing Systems. Expert team on requirements for data from automatic weather stations-Sixth session - Geneva, Switzerland, 22-25 June 2010.

WMO. 2013. Manual on the global observing system. Revised latest edition 2010. 
Open Access This chapter is licensed under the terms of the Creative Commons Attribution 4.0 International License (http://creativecommons.org/licenses/by/4.0/), which permits use, sharing, adaptation, distribution and reproduction in any medium or format, as long as you give appropriate credit to the original author(s) and the source, provide a link to the Creative Commons license and indicate if changes were made.

The images or other third party material in this chapter are included in the chapter's Creative Commons license, unless indicated otherwise in a credit line to the material. If material is not included in the chapter's Creative Commons license and your intended use is not permitted by statutory regulation or exceeds the permitted use, you will need to obtain permission directly from the copyright holder.

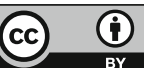

